\title{
How Do Household Financial Obligations Impact the Equity Premium?
}

\author{
Pedram Jahangiry \\ Utah State University
}

\begin{abstract}
In this paper, two specific channels are proposed to investigate how household financial obligations impact the equity premium. Preference channel and borrowing constraints channel. Preferences are defined over households' consumption relative to their financial obligations. The model also introduces dynamic borrowing constraints, using financial obligation ratio as a proxy. A novel feature of the model is that in states of high marginal utility, the borrowing constraint binds and making it more difficult for households to smooth consumption. In addition, in these states, households become more risk averse. This dual mechanism both amplifies the risk premia and makes it time varying.
\end{abstract}

Keywords: asset pricing, equity premium puzzle, incomplete markets, household financial obligation ratio

\section{INTRODUCTION}

Mehra and Prescott (1985), modified a Lucas (1978) type exchange economy to reconcile the standard neoclassical macroeconomic theory with US data on the equity premium. In a consumption-based asset pricing setup, they specify an explicit two-state Markov process for consumption growth and calculate the price of the consumption claim and the risk-free rate. They find that under reasonable parameterization, the model is able, at most, to generate an equity premium of about $0.35 \%$ as opposed to the $6 \%$ premium observed in the data. They call it the "equity premium puzzle" and argue that the mean stock excess return calculated in their calibrated economy is too low, unless the coefficient of relative risk aversion is raised to implausibly high values.

"The ink spilled on the equity premium would sink the Titanic" (John Cochrane, 2008). There is no easy way to summarize the huge literature on the equity premium puzzle. Nevertheless, there is consensus among researchers that, if any, only an absolute asset pricing model would be able to explain the equity premium rather than a portfolio-based model. Absolute pricing model refers to the asset pricing models that use macroeconomic variables such as consumption, labor income, GDP growth and interest rate. After all, portfolio models are relative asset pricing models and are not able to answer questions like why the average returns are what they are or why the expected market return varies over time? To answer these questions, we need to construct a macroeconomic-based asset pricing model. Note that the most basic absolute pricing model - the standard consumption-based model - performs poorly in explaining the historical equity premium puzzle and it fails to explain the cross-sectional variations of expected returns. Hence, proposing a macroeconomic-based asset pricing model with the ability to explain the equity risk premium and the cross-sectional variations of excess returns has been always in the center of attentions among macro-finance researchers.

In the past few decades, there have been many efforts to resolve the puzzle. Various generalizations have been proposed to address the shortcomings of the standard consumption-based model. One approach 
to solve the puzzle is to investigate the preference channel and start with the dependency of marginal utility of consumption on some other variables besides today's consumption. Many current frameworks including habit formation, consumption commitments, heterogenous preferences and employing non-separable utility functions allow for this dependency and indeed this is what has been extensively done in the literature.

Another approach to solve the equity risk premium puzzle is by focusing on the borrowing constraint channel and considering incomplete markets. There is also a large literature on asset pricing with borrowing constraints and margin requirements.

By introducing a single counter-cyclical macroeconomic variable, this paper is the first one connecting the two large literature on asset pricing with borrowing constraints and preference specifications. This paper also contributes to the literature on the relation between households' financial obligations and the equity risk premium.

In my version of the consumption-based asset pricing model, household financial obligations impact the equity risk premium via two separate channels. The first one is the preference channel where individuals' preferences are defined over consumption relative to financial obligations. The framework is analogs to habit formation models where the utility function depends on consumption relative to some habit level (Abel, 1990), (Constantinides, 1990) and (Campbell and Cochrane, 1999). However, in my model the persistence level is observable which is a big advantage over other standard habit models. With this setup, the marginal utility derived from the model is directly related to two components. One is of course the household's consumption and the other one is household financial obligations.

The preference channel is important because one possibility for consumption variation is the potential impact of household's debt level on its preferences. If households are averse to holding large amounts of debt relative to their income, a decline in income will prompt larger declines in consumption among highly indebted households in order to restore the desired debt-to-income ratio for a wide range of loss functions (Scott Baker, 2015). From the other hand, there is evidence that individuals who are more likely to face income uncertainty or to become liquidity constrained exhibit a higher degree of risk aversion in the presence of uninsurable risk (Guiso and Paiella, 2008). By defining households' preferences over consumption relative to financial obligations, the preference channel captures the time varying risk aversion behavior of individuals by featuring fluctuations of consumption net of financial obligations over the business cycles.

The second channel that I investigate in this paper is the borrowing constraint channel which most asset pricing models abstract from. In an infinite horizon aggregate household economy, financial obligations ratio - defined as total debt payments, housing payments and auto lease payments divided by total disposable income - will act as the borrowing constraint in this model. I show that the equity risk premium implied by the model is quiet sensitive to financial obligations ratio as a proxy for borrowing constraints.

But why should the model work? What are the ingredients of the model enabling it to explain and generate the observed equity risk premium in U.S data? The intuition is straight forward. As consumption rises in good times, households take on more debt and the debt payments gradually increase. In bad times consumption falls and households will delever slowly. Thus, debt payments move slowly, following consumption. Now consider a household who has taken a specific level of debt which it must repay. In recessions, as income declines towards this specific level of debt payments, the household reduces its consumption because it is scared, because of risk and risk aversion. Indeed, to make sure that the household can repay its debt payments, it exhibits more risk aversion and takes on less risk. This will decrease the demand for risky assets and increases the demand for precautionary savings in recessions. During booms however, consumption gets further away from the slow-moving financial obligations and hence the investor will become less risk averse and take on more risk. Thus, lower ratio of consumption relative to financial obligations in bad times and higher ratio in good times will directly impact the marginal utility of the household and make the pricing kernel more volatile. This is the households' time varying risk aversion that lead to desires to shift the composition of a portfolio from risky to risk free assets, this is what generates the equity premium.

Also note that in bad times, because of lower income, households face a higher financial obligations ratio. This means that lenders are less willing to lend them in these states of the economy. Thus, households' 
borrowing constraints become binding exactly when they want to smooth consumption. Now since they cannot borrow to consume, they have to either invest less in or liquidate more of their assets. In either case, they will start by the risky assets rather than risk free assets (recall that the model proposed in this paper features a time varying risk aversion and people are more risk averse in recession). The decrease in demand for risky asset is much faster than the decrease in demand for risk free asset. This generates a higher risk premium during recessions. This intuition is consistent with our findings when we relax the borrowing constraint. As we let the household borrow more in bad times, the equity premium shrinks. Time varying borrowing constraints are basically other factors that make households to shift from risky assets to risk free assets.

In summary, a novel feature of the model is that in states of high marginal utility (i.e. in recessions, when income falls) lenders are reluctant to lend, the borrowing constraint binds and making it more difficult for households to smooth consumption exactly when they need to do so. In addition, in these states, households become more risk averse. This dual mechanism both amplifies the risk premia and makes it time varying.

The economic variable explored in this paper - financial obligations ratio - provides a fresh opportunity to investigate the determinants of asset risk. As a start, in a separate research, Jahangiry documents that the risk associated with the aggregate household financial obligations is an economy-wide risk and it is significant for explaining the variations in cross-section of stock returns. Conditioning down on financial obligations ratio, the financial obligations capital asset pricing model (FCAPM) proposed by Jahangiry, survives a wide range of classical econometric and diagnostic tests on explaining the variations in average returns across 25 portfolios formed based on size and book to market ratio. In another study, Jahangiry take one step further and test the predictability of stock returns/excess returns with household's obligations ratio. Using U.S stock market data, he shows that household's debt service ratio is able to predict market returns at short horizon and over business cycle frequencies. Jahangiry argues that mean deviations from debt service ratio is a better forecaster of future returns both in-sample and out-of-sample than several other popular forecasting variables.

The rest of the paper is as follows. In Section 2, I will discuss in details what is the household financial obligations and why does it matter. In section 3, I set up the model and derive the fundamental equations of asset pricing. Section 4 discusses the data and estimations. The results of the model are proposed in Section 5 and section 6 concludes.

\section{HOUSEHOLD FINANCIAL OBLIGATIONS}

Household financial obligations include total debt payments (mortgage debt payments plus consumer debt payments) and total financial commitments (rent, lease, insurance and property tax payments). Financial obligations affect households' optimization behavior. There is an extensive documentation in economic psychology literature studying the psychological impacts of being in debt suggesting that financial obligations are associated with high levels of anxiety and stress, (Brown, Taylor and Price 2005), (Richardson, Elliott and Roberts 2013). And more importantly this impact is independent of the poverty with which it is often associated, (Jenkins, Bhugra, Bebbington and Farrell 2008), (Meltzer, Bebbington, Brugha, and Dennis 2011). Financial obligations also impact households' budget constraints. In particular, if these obligations are high relative to income, and it is not possible to roll over the debt, then borrowers have to cut back on expenditure to avoid default. There is evidence that high financial obligations reduce expenditure at the micro level. The negative effect of a high debt service burden on consumption of households has been shown by (Olney, 1999), (Johnson and Li, 2010), (Dynan, 2012) and (Juseliuse and Drehmann, 2015).

Further the household financial obligations position is really important in determining whether the household is constrained from optimal consumption smoothing. The fact that a household may have been able to borrow in the past does not imply that it can borrow as much in the future. However, household financial obligations alone do not tell us much about this borrowing capability. Imagine two households with the same amount of financial obligations but different levels of income. Most probably the lenders are 
willing to lend to the household with higher income. Hence, we need to define a more indicating variable as a direct proxy of borrowing constraints and that's the financial obligations ratio which we are going to present in next section.

\section{What Is Financial Obligations Ratio (FOR) and Why Does It Matter?}

Households' Financial obligations ratio is defined as the households' total financial obligations divided by their total disposable income. Financial obligations ratio consists of two parts,

1. Total debt service ratio, which is equal to total debt payments divided by total disposable income. Debt payments include all the mortgage debt payments and consumer debt payments including auto loans, student loans and consumer credit cards.

2. Total financial commitment ratio, which is equal to total financial commitments divided by total disposable income. Financial commitments include all the rent payments, lease payments, insurance and property tax payments of the homeowners.

\section{Properties of Financial Obligations Ratio}

Since 1980 onward, Federal Reserve Board has reported the financial obligations ratio for U.S households. FIGURE 1 shows that household financial obligations ratio is a time varying macroeconomic variable with the average of $16.40 \%$. As FIGURE 1 suggests, financial obligations ratio tends to move counter-cyclically over the business cycles.

FIGURE 1 FINANCIAL OBLIGATIONS RATIO AS A PERCENT OF DISPOSABLE INCOME

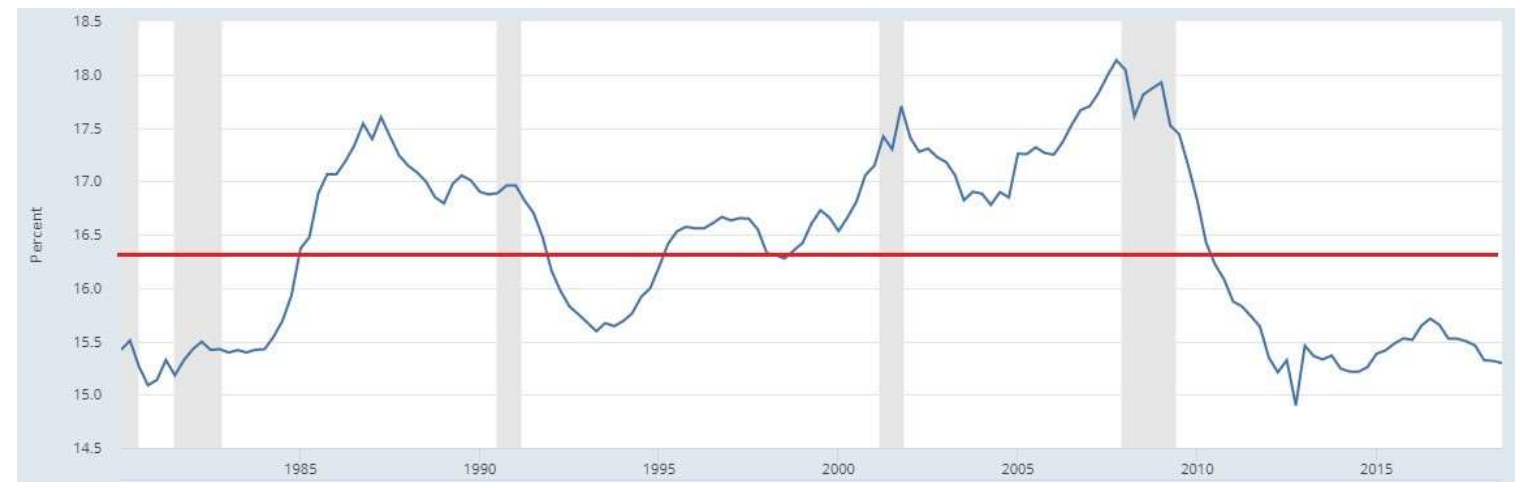

While the economy stays in good times, consumers keep spending more and hence increasing their financial obligations, now when the economy is hit by a negative shock (recession) this is the time that financial obligations are already high and people cannot smooth their consumption exactly when they need to do so. Hence what we observe in the data is that financial obligations ratio is high almost in the early stage of every recession because households are carrying a huge amount of obligations from previous good old days and then the ratio decreases as the economy recovers and households delever.

Higher financial obligations ratio also implies less investment in risky assets. This is due to the fact that when households are overextended, even a small income shortfall prevent them from smoothing consumption and making new investments (Drehmann and Juselius, 2012). FIGURE 1 also shows that almost after every recession, the financial obligations ratio pulls back to lower levels which is true because of the households' higher income during booms. There is also another reason in the following manner, when household obligations ratios are high and unemployment is rising, lenders may respond to the expected increase in defaults by limiting the availability of credit and this leads to lower aggregate payments and finally lower obligation ratio. Thus, financial obligations ratio has a counter-cyclical property. Shaded areas in FIGURE 1 indicate US recession periods. Other important properties of financial obligations ratio which make it the variable of interest in this paper are as follows: 
- All the components of the financial obligation's ratio are observable so when working with data, there is no need to come up with questionable proxies.

- Financial obligations ratio is directly related to the interest rate. By construction, the higher the interest rate, the higher the payments and the higher the financial obligations. This explicit dependency establishes a direct link between obligation ratios and predictability of stock market returns. (Juselius and Drehmann, 2015) argue that "the average lending rate reflects not only current interest rate conditions, but also past money market rates, past inflation and interest rate expectations as well as past risk and term premia. This implies that the lending rate, and hence the debt service ratio, is chiefly influenced by current and past monetary policy decisions".

- Financial obligations ratio captures the burden of obligations on the households more accurately than the established debt-to-GDP ratio. More specifically financial obligations ratio accounts for changes in interest rates and also maturities that affect households' repayment capacity.

- (Drehmann and Juselius, 2012) found that the debt service ratio, which is the main part of financial obligations ratio, produces a very reliable early warning signal ahead of systemic banking crises. In the context of absolute asset pricing this is really important because we are looking for a conditioning down variable which is correlated with business cycles specially with bad times.

- Financial obligations ratio can be used as a direct indicator of borrowing constraints. (Johnson and $\mathrm{Li}, 2010$ ) tested the proposition that a higher debt service ratio increases the likelihood of credit denial. So, household's obligation ratio is a critical input for lending institutions in order to provide the households with more leverage.

Given the aforementioned properties for financial obligations ratio and the fact that expected returns vary with business cycles, we are going to explore how these obligations impact the equity risk premium.

\section{THE MODEL}

\section{Environment}

I will consider an infinite horizon endowment economy in which the agents are endowed with an uninsurable stochastic income at each period. The agents in this economy are:

1. Large number of homogeneous households

2. A lending institution

In this paper, I use a modified version of Greenwook-Hercowitz-Huffman utility structure which enable us to represent the aggregate households with a representative agent. Thus, we have a representative agent environment with an external supply of debt provided by lending institutions. This can be thought of as small open economy. It is assumed that the lending institution is aware of the income distribution of the representative agent. There are three assets and two markets in this economy. The assets are one perishable consumption good and two durable assets, an inside security and an outside security (debt instrument). The inside security provides dividends according to an exogenous stochastic process and the outside security is exogenously supplied by the lending institution. The environment is summarized in TABLE 1. 


\section{TABLE 1}

\section{THE MODEL ENVIRONMENT}

\begin{tabular}{ll}
\hline \multicolumn{1}{c}{ Capital Market } & \multicolumn{1}{c}{ Debt Market } \\
\hline Households & Households + A lending institution \\
One inside security & One outside security \\
Zero net supply & Positive net supply \\
No trade equilibrium & Exogenous prices \\
\hline
\end{tabular}

The two markets in the model are:

1. The capital market which is a market for allocating idiosyncratic risk among households. In this capital market everything is in zero net supply. Households can trade contingent claims (inside security) among themselves but since all the households are identical, the prices are going to be shadow prices for no-trade equilibrium.

2. The debt market in which there is an outside supply of debt (outside security) provided by a lending institution. I am not going to model the supply side of the debt market. The lending rate is an exogenously specified rate. The households can borrow from this lending institution up to a certain amount defined by their financial obligations ratio.

\section{Constraints}

In each period, households are endowed with a stochastic exogenous income which they can either consume or invest in inside security. They are allowed to borrow against their stochastic income and use it only for consumption purposes. The model will have a non-stationary environment due to non-stationarity of the stochastic aggregate income and the exogenous dividends of inside security. However, the exogenous stochastic borrowing rates are stationary. Consumption, financial obligation, dividends, aggregate disposable income, prices of the equity and the risk-free bond are all denominated in units of the consumption good.

In the model, for each period $t, C_{t}$ is the aggregate consumption. $Y_{t}$ is the aggregate disposable income and $X_{t}$ represents the dividends generated by the inside security. By making the wage income process exogenous, I abstract from the labor-leisure trade-off. This means that the labor is supplied inelastically and the labor leisure choice is not modeled. $D_{t}$ is the debt service level borrowed by the representative agent at the gross rate $R_{t}^{d}$. I assume that the lending institutional arrangements can issue and redeem debt instruments. This lending institutions exogenously set a lending cap $\theta_{t}$ on each household. Hence $\theta_{t}$ provides a state dependent upper bound for the households' borrowing capacity. $Z_{t}$ is a non-negative amount of investment in inside security with an ex-dividend price of $p_{t}$ at time $t$. The agent faces the following constraints:

- Budget constraint

$$
C_{t}+p_{t} Z_{t}+D_{t-1} R_{t-1}^{d} \leq Y_{t}+\left(p_{t}+X_{t}\right) Z_{t-1}+D_{t}
$$

- Financial obligations constraint

$$
D_{t} R_{t}^{d} \leq \theta_{t} Y_{t} \quad, \quad D_{t} \geq 0
$$

Inequality (1) is the budget constraint that the agents face in each period. The agent comes into the period with a stochastic wage income $Y_{t}$. There is also income from securities purchased in last period. Agent can liquidate $Z_{t}$ amount of inside security at price $p_{t}$ with the dividend $X_{t}$. Furthermore the agent can borrow against his stochastic income at the amount of $D_{t}$. These are resources of funds. Now the left- 
hand side of (1) will show us how does the agent spend the available funds. First of all, he consumes $C_{t}$, then he can purchase inside security to take over to the next period and finally he has to pay interest on debt that he had borrowed. $R_{t-1}^{d}$ is the gross return on debt instrument and it means that the agent has to payback whatever he has borrowed in last period plus the interest. At $t=0$ the representative agent is born debt free $D_{-1}=0$, and he is endowed with nothing but a stochastic income $Y_{0}$ i.e, $Z_{0}=0$.

Inequality (2) is the borrowing constraint. It basically indicates how much the agent can borrow against its labor income. This financial obligation ratio constraint (2) is a type of constraint that we observe in the economy. Interest payments on debt over income is a number that lenders would rather to see it below some certain levels like $1 / 3$ or $1 / 4$ and this number varies from time to time. (2) is a constraint that I impose in this model and that's one of the innovations of the model, the borrowing constraint channel. The innovation is introducing a State dependent, time-varying borrowing constraint. I am making the borrowing capacity to be state dependent. In bad times financial obligations ratio gets higher (due to negative income shock) and agent's borrowing capability thereafter shrinks. This force the agent to reduce its consumption in bad times even further. Note that the income $Y_{t}$, dividends $X_{t}$ and obligation ratio cap $\theta_{t}$ are all exogenous stochastic variables. For calculation purposes, we work with detrended income $y_{t}$ and dividend growth $x_{t}$ which are determined by the following Markov processes:

$y_{t+1}=\left(1-\rho_{y}\right) \bar{y}+\rho_{y} y_{t}+\epsilon_{t+1}^{y}$

$x_{t+1}=\left(1-\rho_{x}\right) \bar{x}+\rho_{x} x_{t}+\epsilon_{t+1}^{x}$

In equations (3) and (4), $\bar{y}$ and $\bar{x}$ are the averages of detrended aggregate income and dividend growth respectively. $\rho_{y}$ and $\rho_{x}$ are the auto correlations and epsilons are the relevant shocks associated with $y$ and $x$. Finally, the exogenous process for financial obligations ratio cap $\theta_{t}$ is defined as in (5).

$E_{t}\left(\theta_{t+1} \mid y_{t}\right)=f\left(y_{t}\right)$

Equation (5) implies that the process of $\theta$ is totally pinned down by the process of $y$. This assumption is very intuitive as the lending institution is the one that sets $\theta$ exogenously and it is aware of household's income distribution. Timing of the constraints are as follows. At time $t$, the agent knows at what rate he will be able to borrow, so $R_{t}^{d}$ is measurable with respect to time $t$. According to the financial obligations' constraint in (2), $D_{t}$ is also measurable at time $t$. Thus, the only random variables here are $Y$ and $\theta$. Note that there will be no default in this model. Under my parameterization, the agent can always reduce his consumption such that he has a positive net worth. In other word he will never have a realization of $Y$ so low at which he cannot pay off his debt by reducing consumption. And besides, lenders are going to choose $\theta$ conditional on some expectation of future income of the agent. So, if lenders' conditional expectation of future income is low, they will lower the $\theta$ to make sure that agent is going to be able to pay off his debts. Hence the lender is building the expectations of $\theta_{t+1}$ based on $y_{t}$. It means that when expected income is low, the lender will react by decreasing $\theta_{t+1}$ conditional on $y_{t}$ such that the conditional expectation of $\theta$ is

lower than it's expected value i.e. $E_{t}\left(\theta_{t+1} \mid Y_{t}\right) \leq \bar{\theta}$. In short, in this model, the lender is the one monopolist and everybody else is a price taker. This monopolist has some expectations of agents' income and is going to reduce the amount that agents can borrow, precisely when they would like to borrow next period. This is the building block of my model and it basically shows that how the model generates a more volatile marginal utility. In bad times the effective consumption (consumption net of financial obligations) is smaller and in good times it is bigger than the standard consumption in Mehra-Prescott world. Thus, with this set up, everything will be conditional on $Y_{t}$. The variations in marginal rate of substitution is going to determine the returns on inside security and hence this is the extra variations in dividends that is going to generate a higher equity premium. 


\section{The Preferences}

The utility function presented here will show us how the financial obligations ratio impacts the equity risk premium via the preference channel. In my model, the agent's preference is defined over consumption relative to financial obligations $G$. This is a behavioral set up which is analogous to habit formation models; In the sense that, while in the latter model "the distance from consumption habit" gives the agent utility, in the former case "the distance from financial obligation" does the same job. More specifically, I will use the simple power utility function defined over the representative agent's effective consumption $C^{*}$, where $C^{*}$ is the consumption net of financial obligations incorporating the distance from the financial obligations. Effective consumption is defined as $C_{t}^{*}=C_{t}-G_{t}$ where $G_{t}=D_{t-1} R_{t-1}^{d}$ is the financial obligations that the agent carry over to period $t$ from the last period. Hence the utility function of the agent is,

$U\left(C_{t}^{*}\right)=\frac{C_{t}^{*(1-\gamma)}}{1-\gamma}=\frac{1}{1-\gamma}\left(C_{t}-G_{t}\right)^{(1-\gamma)}$

Equation (6) suggests that a household with lower financial obligations will have a higher effective consumption and hence receives a higher utility. This behavioral set up is chosen because there is an extensive documentation in economic psychology literature studying the psychological impacts of being in debt. Indeed, financial obligations are associated with high levels of anxiety and stress (Brown, Taylor and Price, 2005), (Richardson, Elliott and Roberts, 2013). And more importantly This impact is independent of the poverty with which it is often associated (Jenkins, Bhugra, Bebbington and Farrell, 2008), (Meltzer, Bebbington, Brugha, and Dennis, 2011). This is the behavioral reason of why we should include financial obligations in the utility function. There is also a structural reasoning behind the choice of effective consumption as in difference form $(C-G)$, rather than ratio form $\left(\frac{C}{G}\right)$. I pick the difference form because it generates a time varying relative risk aversion. However, there is no consensus on pro-cyclicality or counter-cyclicality of the relative risk aversion. Risk aversion is counter-cyclical in habit formation models (in recession, consumption surplus ratio is lower so risk aversion is higher) and pro-cyclical in happiness maintenance models (in good times you become more risk averse as you wish good days never end). Time varying risk aversion plays an important role in determining the equity premium, especially during recessions. Because "recessions are phenomena of risk premiums, risk aversion, risk bearing capacity and desires to shift the composition of a portfolio from risky to risk free assets, a flight to quality, not a phenomenon of intertemporal substitution, a desire to consume more tomorrow vs. today" (John Cochrane, 2016). Also note that in this model, $C_{t}-G_{t}$ is always positive. People slowly develop financial obligations, so consumption is always greater than debt obligations (no- default assumption), indeed financial obligations form the trend in consumption.

With this specification in (6), the coefficient of relative risk aversion is going to be (7)

$R R A=-C \frac{u \prime(C)}{u^{\prime}(C)}=\gamma\left(\frac{1}{\frac{C-G}{C}}\right)=\frac{\gamma}{S}$

where $S=\frac{C-G}{C}$ is the consumption surplus. This is analogous to (Campbell and Cochrane, 1999) habit model with financial obligations replacing the consumption habit. It is very important to emphasize that the persistence level in my model is observable which is a big advantage to Campbell and Cochrane external habit model in which the habit level is not observable. However, the idea is the same, in bad times, as consumption or the surplus consumption ratio $S$ decreases, agent's relative risk aversion rises i.e. the same proportional risk to consumption is a more fearful event when consumption starts closer to financial obligations, $G$.

The link between consumption surplus $S$ and the financial obligations ratio is straight forward. Financial obligations $G$ is like a slow-moving habit in this model. In recessions, when a negative shock to the aggregate income is realized, it will increase the current financial obligations ratio of the representative 
agent. According to the budget constraint (1) and the borrowing constraint (2), the agent has no option but to decrease its consumption $C_{t}$. This is true because of three reasons. First, there is a no-trade equilibrium, the representative agent doesn't have the option of liquidating its assets. Second, I am implicitly assuming that the agent cannot default on its debt payments so it has to pay back $D_{t-1} R_{t}^{d}$ in full and third, in bad times the financial obligations ratio is already capped so the agent cannot leverage any more. This will make the consumption closer to slow-moving obligation $G$ and hence reduce the consumption surplus $S$. Hence in recessions (negative income shocks), financial obligations ratio is high, consumption surplus is low and relative risk aversion is high. This enables the model to deliver a time-varying, recession-driven equity risk premium.

\section{Stochastic Sequential Problem}

The representative agent maximizes the following sequential problem:

$\operatorname{Max} \quad E_{0}\left\{\sum_{t=0}^{t=\infty} \beta^{t} U\left(C_{t}^{*}\right)\right\}$

where $U\left(C_{t}^{*}\right)=\frac{C_{t}^{* 1-\gamma}}{1-\gamma}$ and $C_{t}^{*}=C_{t}-G_{t}$. Subject to the budget constraint (1), borrowing constraint (2), exogenous stochastic processes (3)-(5) and the non-negativity constraints.

$$
\begin{aligned}
& G_{t}=D_{t-1} R_{t-1}^{d} \\
& C_{t}+p_{t} Z_{t}+D_{t-1} R_{t-1}^{d} \leq Y_{t}+\left(p_{t}+X_{t}\right) Z_{t-1}+D_{t} \\
& D_{t} R_{t}^{d} \leq \theta_{t} Y_{t} \\
& y_{t+1}=\left(1-\rho_{y}\right) \bar{y}+\rho_{y} y_{t}+\epsilon_{t+1}^{y} \\
& x_{t+1}=\left(1-\rho_{x}\right) \bar{x}+\rho_{x} x_{t}+\epsilon_{t+1}^{x} \\
& E_{t}\left(\theta_{t+1} \mid y_{t}\right)=f\left(y_{t}\right) \\
& C_{t} \geq 0 \quad, \quad D_{t} \geq 0 \quad, \quad Z_{t} \geq 0 \\
& \text { Given } X_{0}, Y_{0}, R_{0}^{d} \quad, \quad Z_{0}=D_{-1}=0
\end{aligned}
$$

For simplification purposes, I assume the exogenous lending rate is constant and equal to $R_{t}^{d}=\bar{R}^{d}$. The transversality condition holds for financial obligations which implies that the shadow value of debt service must be equal to zero in the limit. We also assume Inada conditions on effective consumption. The economy is completely specified by the preference parameters $\beta, \gamma$ and realization of the stochastic processes followed by $\Lambda_{t}=\left(y_{t}, x_{t}, \theta_{t}\right)$. The equilibrium is defined as the sequences of consumption $\left\{\widetilde{C}_{t}\right\}$, investment $\left\{\widetilde{Z_{t}}\right\}$, borrowing decisions $\left\{\widetilde{D_{t}}\right\}$ of the representative agent and the prices $p_{t}$ such that:

1. Taking the prices and exogenous vector $\Lambda$ as given, sequences of consumption, investment and borrowing decisions, optimize the households' lifetime expected utility.

2. Consumption, capital and debt markets clear in all periods. Note that there is no need to clear the debt market; as mentioned earlier, debt service rates are exogenously determined.

\section{Pricing Kernel}

Given the utility function in (6), the intertemporal marginal rate of substitution (The pricing Kernel) is: 
$M_{t+1}=\beta \frac{U_{c}\left(C_{t+1}^{*}\right)}{U_{c}\left(C_{t}^{*}\right)}=\beta\left(\frac{C_{t+1}}{C_{t}}\right)^{-\gamma}\left(\frac{S_{t+1}}{S_{t}}\right)^{-\gamma}$

where $S_{t}=\frac{C_{t}-G_{t}}{C_{t}}$. The pricing Kernel is related to consumption growth and consumption surplus which depends on financial obligations and is an implicit state variable in my model. We can now calculate moments of the marginal rate of substitution (7) and find asset prices. Taking the first order conditions (FOC) with respect to $C_{t}, D_{t}$ and $Z_{t}$ and combining the results will give us the "fundamental equations of asset pricing". From FOC $\left(\left[C_{t}\right],\left[Z_{t}\right]\right)$ we get the price of inside security:

$p_{t}=E_{t}\left(\beta\left(\frac{c_{t+1}}{c_{t}}\right)^{-\gamma}\left(\frac{s_{t+1}}{s_{t}}\right)^{-\gamma}\left(p_{t+1}+X_{t+1}\right)\right)$

Now with equation (18) in hand we can derive the price of any inside security given its dividend. To calculated the equity risk premium, we need the price of risk-free bond $q_{t}$. Using (18) and the fact that nocoupon treasury bonds are traded in discounted values, then the price of risk-free bond is equal to:

$q_{t}=E_{t}\left(\beta\left(\frac{C_{t+1}}{c_{t}}\right)^{-\gamma}\left(\frac{s_{t+1}}{s_{t}}\right)^{-\gamma} 1\right)$

Market clearing condition imply that $Z_{t}=0 \quad \forall t \geq 0$; this is because every household is the same and the equilibrium outcome must be the no-trade outcome. We are interested in finding the prices that support this no trade outcome. From market clearings and budget constraint, the equilibrium consumption sequence is:

$C_{t}=Y_{t}+D_{t}-D_{t-1} R_{t}^{d}$

Now we are only one step away from finding an explicit form solution for the equity price and riskfree bond price. Fortunately, it is easy to show that the debt service ratio constraint in (2) is binding. Note that at each period $t$, the utility function $U_{t}$ is strictly increasing in consumption $C_{t}$, so the budget constraint and the borrowing constraint binds to guarantee that the agent is maximizing. However, one may argue that as financial obligations increase, the effective consumption will also decrease. This is not true here, since current obligations $G_{t}$ is a function of last period debt service $D_{t-1}$ and not the current borrowings $D_{t}$. This means that the representative agent will cap the amount of borrowings. This will pave the way for calculating the equity premium and the risk-free rate implied by the model. Now using the Equilibrium consumption path in (20) accompanying with equations (18) and (19), it gives us the fundamental equations of asset pricing at the equilibrium. Note that it is convenient to define $w_{t}=\frac{p_{t}}{x_{t}}$ as the price-dividend ratio because it will allow us to write down the equilibrium equity returns in terms of dividend growth, which is stationary and not the dividend itself, which is non-stationary. Thus, by dividing both sides of (18) to $X_{t}$, we can rewrite (18) as:

$w_{t}=\beta E_{t}\left\{\left(\frac{c_{t+1}}{c_{t}}\right)^{-\gamma}\left(\frac{s_{t+1}}{s_{t}}\right)^{-\gamma}\left(1+w_{t+1}\right)\left(\frac{X_{t+1}}{X_{t}}\right)\right\}$

The right-hand side of (8) is a conditional expectation, by applying the Low of Iterated Expectations we are allowed to take $X_{t}$ into the conditional expectation. Where, $\frac{X_{t+1}}{X_{t}}$ is the dividend growth. Next we can use (19) and (21) to solve for the risk-free rate $R_{t}^{f}$, Equity returns $R_{t}^{e}$ and consequently the Equity Premium $E P_{t}$. Starting with the risk-free rate and using (19) we have: 
$R_{t}^{f} \quad=\frac{1}{q_{t}}=\frac{1}{\beta E_{t}\left(\left(\frac{c_{t+1}}{c_{t}}\right)^{-\gamma}\left(\frac{s_{t+1}}{s_{t}}\right)^{-\gamma}\right)}$

The equity return can be derived as:

$R_{t+1}^{e}=E_{t}\left(\frac{p_{t+1}+X_{t+1}}{X_{t}}\right)=E_{t}\left(\frac{w_{t+1} X_{t+1}+X_{t+1}}{w_{t} X_{t}}\right)=E_{t}\left\{\left(\frac{X_{t+1}}{X_{t}}\right)\left(\frac{1+w_{t+1}}{w_{t}}\right)\right\}$

where $w_{t}$ is defined as in (21). And finally, the equity premium is simply defined as (23) minus (22):

$E P_{t}=E_{t}\left(R_{t+1}^{e}\right)-R_{t}^{f}$

At the end, if the exogenous variables follow Markov processes, then solving functional equations in (22) and (23) is just solving a finite system of linear equations. Thus, defining the exogenous stochastic processes for the aggregate real income and dividend growth rate, we can now test the model by comparing the observed equity premium and risk-free rates in U.S data to the ones implied by the model.

It is worth emphasizing that the model deals with non-stationary environment because of nonstationarity of aggregate dividends and aggregate income. This enables the model to generate a nonstationary equilibrium consumption path, a non-stationary equity prices and a stationary equity premium which is consistent with the data. Note that the risk-free bond prices generated by (19) are stationary because $q_{t}$ only depends on consumption growth and financial obligations growth which are both stationary

\section{DATA AND ESTIMATIONS}

The numerical goal is to compare the equity risk premium observed in U.S data with the one generated by the model presented in this paper. I use annual data for the period between 1980 and 2018 to report the equity premium observed in the data. TABLE 2 summarizes the data source.

\section{TABLE 2 \\ DATA SOURCE}

\begin{tabular}{ll}
\hline \multicolumn{1}{c}{ Variables } & \multicolumn{1}{c}{ Data source (1980-2018) } \\
\hline S\&P composite prices and dividends & Robert J. Shiller Data \\
The 1-month T-bill returns & CRSP: Center for Research in Security Prices \\
Consumer Price Index (CPI) & U.S. Bureau of Labor Statistics \\
Aggregate income per capita & National Income and Product Accounts (NIPA) \\
Household Financial Obligations Ratio & Federal Reserve Bank of St. Louis \\
\hline
\end{tabular}

We also need to estimate the equity premium implied by the model in a calibrated endowment economy. Generally, the solutions to asset pricing equations (18) and (19) are not available in an analytically simple closed form. However, there are instances where calculation of the exact solution or a good approximation to that, is possible. In my model the binding borrowing constraints does the job and make it possible to solve for the closed form solutions. Indeed, solutions to functional equations (22) and (23) depends on values of three exogenous stochastic processes for $y_{t}, x_{t}$ and $\theta_{t}$. Note we have already assumed that $R_{t}^{d}$ is constant and equal to $\overline{R^{d}}$. More specifically, I will use weighted average annual rate of commercial bank interest rate on credit cards and 1-Year adjustable rate mortgage, the average gross borrowing rate would be equal to 1.085. A typical problem is to characterize the price of an asset, where the law of motions for exogenous stochastic state variables are AR (1) processes. Now we need to check whether the stochastic processes for $y$ and $x$ are stationary over time and then estimate them with an AR(1) process. TABLE 3 
summarized the results for stationarity tests for detrended aggregate income and divided growth using two different methods, namely Augmented Dicky-Fuller unit root test (ADF), and Kwiatkowski-PhillipsSchmidt Shin (KPSS) stationarity test.

As TABLE 3 suggests, the ADF test statistics for detrended income $y$ and aggregate dividend growth $x$ are equal to -5.343 and -5.042 respectively, meaning that we can reject the null hypothesis (Null: $y_{t}$ and $x_{t}$ exhibit unit root property). Also using KPSS test, we cannot reject the null hypothesis that the variables are stationary over time as the test statistics are smaller than the critical values. Thus, it is reasonable to estimate the stochastic processes for income and dividend growth with an autoregressive process AR(1). The last step to derive a numerical closed form solution and generating the equity risk premium implied by the model is to discretize AR(1) processes for income and divided growth. I will use (Rouwenhorst, 1995) technique to discretize the AR processes. In this paper, Rouwenhorst method is preferred to (Tauchen, 1986) approach because of the following reasons. First, the residuals of both AR(1) processes pass the ARCH heteroskedasticity test i.e. we can reject heteroskedasticity of residuals. Second, I am going to discretize the economy with a 2-state Markov process for each $y$ and $x$. When the number of states is small (equal to 2 here), the Rouwenhorst technique outperforms the Tauchen approach. Note that the AR(1) stochastic processes for income and dividend growth are as follow:

$$
\begin{aligned}
& E P_{t}=E_{t}\left(R_{t+1}^{e}\right)-R_{t}^{f} \\
& x_{t+1}=\left(1-\rho_{x}\right) \bar{x}+\rho_{x} x_{t}+\epsilon_{t+1}^{x}
\end{aligned}
$$

\section{STATIONARITY TEST OR EXOGENOUS VARIABLES}

\begin{tabular}{lccccc} 
& ADF test statistic & \multicolumn{3}{c}{ KPSS test statistic } \\
& $y_{t}$ & & $x_{t}$ & $y_{t}$ & $x_{t}$ \\
& -5.34 & & -5.04 & 0.243 & 0.273 \\
\hline 1\% level & & -3.64 & & \multicolumn{2}{c}{0.74} \\
$5 \%$ level & & -2.96 & & 0.46 & \\
$10 \%$ level & & -2.62 & & 0.35 & \\
\hline
\end{tabular}

In my model, the stochastic process for financial obligations cap is fully determined by the process for aggregate income. TABLE 4 summarized the estimated parameters of AR (1) processes.

TABLE 4

AR(1) ESTIMATIONS

Parameter/Variable Description

\begin{tabular}{lll}
\hline$y$ & Normalized labor income per capita (detrended) & $1, \rho_{y}=0.64, \epsilon_{y}=0.08$ \\
$x$ & Dividend growth & $.032, \rho_{x}=0.61, \epsilon_{x}=0.05$ \\
$\theta$ & Financial obligations ratio cap & $\bar{\theta}=0.165, \quad \sigma_{\theta}=0.009$ \\
\hline
\end{tabular}

The economy is completely specified by realization of the joint stochastic process followed by the aggregate real income and dividend growth. I model the joint process of the aggregate income and the dividend growth as a time-stationary Markov chain with a nondegenerate, unique, stationary probability distribution. Starting with the real aggregate income, I assume that $y_{t}$ follows a 2-states Markov chain $\left(y, Q, \pi^{Y}\right)$ where $y$ is the state vector, $Q$ is a 2-by-2 transition matrix and $\pi^{Y}$ is the probability distribution. 
The two states are High and Low standing for high and low aggregate income during boom and recession respectively. So, I define the states vector $y$ as:

$y=\left(y^{H}, y^{L}\right)=\left(\mu^{Y}+\delta^{Y}, \mu^{Y}-\delta^{Y}\right)$

where $\mu^{Y}$ is the long run aggregate income and $\delta^{Y}$ is its standard deviation. The probability distribution $\pi^{Y}$ is defined as:

$\pi_{i j}^{R}=\operatorname{Pr}\left(y_{t+1}=y_{j} \mid y_{t}=y_{i}\right)$

Then the transition matrix $Q$ is symmetric with:

$Q=\left[\begin{array}{ll}q_{11} & q_{12} \\ q_{21} & q_{22}\end{array}\right]=\left[\begin{array}{cc}\pi_{11}^{Y} & 1-\pi_{11}^{Y} \\ 1-\pi_{22}^{Y} & \pi_{22}^{Y}\end{array}\right]=\left[\begin{array}{cc}\phi^{Y} & 1-\phi^{Y} \\ 1-\phi^{Y} & \phi^{Y}\end{array}\right]$

where $\phi^{Y}$ is the long run auto correlation coefficient of $y$. Next, I assume that dividend growth $x_{t}$ also follows a 2-states Markov process $\left(x, P^{k}, \pi^{X}\right)$ where $x$ is the state vector, $P^{k}$ is a 2-by-2 transition matrix where $k: H, L$ meaning that transition matrix for $x$ depends on whether $y$ is in high or low state. Also $\pi^{X}$ is the probability distribution. Again the 2 states are High and Low standing for high and low dividend growth. I define the states vector $x$ as:

$x=\left(x^{H}, x^{L}\right)=\left(\mu^{X}+\delta^{X}, \mu^{X}-\delta^{X}\right)$

where $\mu^{X}$ is the long run aggregate dividend growth and $\delta^{X}$ is its standard deviation. The probability distribution $\pi^{X}$ is defined as:

$\pi_{i j}^{X}=\operatorname{Pr}\left(x_{t+1}=x_{j} \mid x_{t}=x_{i}\right)$

Then the transition matrix $P^{k}$ is symmetric with:

$P^{k}=\left[\begin{array}{cc}\pi_{11}^{X} & 1-\pi_{11}^{X} \\ 1-\pi_{22}^{X} & \pi_{22}^{X}\end{array}\right]=\left[\begin{array}{cc}\phi_{k}^{X} & 1-\phi_{k}^{X} \\ 1-\phi_{k}^{X} & \phi_{k}^{X}\end{array}\right]$

where $\phi_{k}^{X}$ is the long run auto correlation coefficient of $x$ conditional on whether $y$ is in it's high ( $\left.k: y_{H}\right)$ or low $\left(k: y_{L}\right)$ states. So, the exogenous joint stochastic processes for $y$ and $x$ follows a 4-state coupled Markov chain with a 1-by-4 probability distribution $\pi$ and a 4-by-2 state matrix $y x$ :

$y x=\left[\begin{array}{l}y x_{H H} \\ y x_{H H} \\ y x_{H H} \\ y x_{H H}\end{array}\right]=\left[\begin{array}{ll}y_{H} & x_{H} \\ y_{H} & x_{L} \\ y_{L} & x_{H} \\ y_{L} & x_{L}\end{array}\right]$

and a 4-by-4 transition matrix $S_{Y X}$ :

$S_{Y X}=\begin{array}{cccc}H H & H L & L H & L L \\ H H & H H \\ & L L\end{array}\left(\begin{array}{llll}s_{11} & s_{12} & s_{13} & s_{14} \\ s_{21} & s_{22} & s_{23} & s_{24} \\ s_{31} & s_{32} & s_{33} & s_{34} \\ s_{41} & s_{42} & s_{43} & s_{44}\end{array}\right)$ 
where $s_{i j}$ can be calculated directly from transition matrices $Q$ and $P$. For example, this is how we derive $s_{12}=S_{Y X_{H L, H H}}$,

$$
s_{12}=S_{y x_{H L H H}}=\operatorname{Pr}\left(y x_{t+1}=y x_{H L} \mid y x_{t}=y x_{H H}\right)=\operatorname{Pr}\left(\begin{array}{l|l}
y_{t+1}=y_{H} & y_{t}=y_{H} \\
x_{t+1}=x_{L} & x_{t}=x_{H}
\end{array}\right)
$$

$s_{12}=\operatorname{Pr}\left(x_{t+1}=x_{L}, \mid x_{t}=x_{H}, y_{t}=y_{H}\right) * \operatorname{Pr}\left(y_{t+1}=y_{H}, \mid y_{t}=y_{H}\right)=P_{12}^{H} * q_{11}$

where $P_{12}^{H}$ is the 1,2 elements of the matrix $P^{H}$. Similar reasoning leads to the following transition matrix for $S_{Y X}$.

$$
S_{Y X}=\left(\begin{array}{cc|cc}
P_{11}^{H} q_{11} & P_{12}^{H} q_{11} & P_{11}^{L} q_{12} & P_{12}^{L} q_{12} \\
P_{21}^{H} q_{11} & P_{22}^{H} q_{11} & P_{21}^{L} q_{12} & P_{22}^{L} q_{12} \\
& & & \\
P_{11}^{H} q_{21} & P_{12}^{H} q_{21} & P_{11}^{L} q_{22} & P_{12}^{L} q_{22} \\
P_{21}^{H} q_{21} & P_{22}^{H} q_{21} & P_{21}^{L} q_{22} & P_{22}^{L} q_{22}
\end{array}\right)=\left(\begin{array}{ll}
P^{H} q_{11} & P^{L} q_{12} \\
P^{H} q_{21} & P^{L} q_{22}
\end{array}\right)
$$

It is easy to confirm that $S_{Y X}$ is a bona-fide transition matrix. In summary, to solve the model we need to estimate the parameters in TABLE 5.

\section{TABLE 5}

\section{ESTIMATED PARAMETERS AND VARIABLES}

\begin{tabular}{cl}
\hline Item & \multicolumn{1}{c}{ Description } \\
\hline$\beta$ & Constant discount factor - time preference \\
$\gamma$ & Coefficient of relative risk aversion \\
$\theta$ & Exogenous predetermined upper bound for FOR \\
$\mu^{Y}$ & Long run average annual aggregate income (detrended) $y$ \\
$\delta^{Y}$ & Standard deviation of annual $y$ \\
$\phi^{Y}$ & First order autocorrelation coefficients of annual $y$ \\
$\mu^{X}$ & Long run average aggregate dividend growth $x$ \\
$\delta^{X}$ & Standard deviation of annual $x$ \\
$\phi_{k}^{X}$ & First order autocorrelation coefficients of annual $x$ for $k: H, L$. \\
\hline
\end{tabular}

The acceptable value for $\beta$ based on different macroeconomic models ranges from 0.95 to 0.99 . I set $\beta=0.98$ and let the coefficient of relative risk aversion $\gamma$ vary from 1 to 3 . In the result section of the paper I show that -unlike in the standard consumption-based model- our model is able to get close to the 
equity risk premium observed in U.S data even for these small values of risk aversion. The rest of the parameters and variables are estimated as illustrated in TABLE 6.

TABLE 6

ESTIMATED VALUES FOR THE MARKOV PROCESSES

\begin{tabular}{cc}
\hline Parameter & Estimated value \\
\hline$\mu^{Y}$ & 1.00 \\
$\delta^{Y}$ & 0.06 \\
$\phi^{Y}$ & $\frac{1+\rho_{y}}{2}=\frac{1+0.64}{2}=0.82$ \\
$\mu^{X}$ & 1.04 \\
$\delta^{X}$ & 0.07 \\
$\phi_{k}^{X}$ & $\frac{1+\rho_{x}}{2}=\frac{1+0.61}{2}=0.805$ \\
\hline
\end{tabular}

\section{RESULTS}

In this section, I show that the model is able to get close to equity risk premium observed in U.S data while keeping the risk-free rate low. TABLE 7 summarizes the results for different specifications of the model. As TABLE 7 suggests, the model presented in this paper completely outperform the standard consumption model in explaining the equity risk premium observed in the data. The equity premium puzzle states that the mean excess return calculated in the standard consumption-based model is too low unless the coefficient of relative risk aversion is implausibly high. For the standard model this number is 20 which makes no economic sense. However, in this paper, the model generates an equity premium of $4.62 \%$ while the utility curvature is only 3 . This is consistent with the intuition of our model. In bad times, as consumption gets closer to household's financial obligation, people become more risk averse (as they have to pay back their obligations) and take on less risk. This leads to less investment in the risky asset and higher equity risk premium eventually. Another advantage is that unlike the standard model, this model keeps the risk-free rate relatively stable and low. For the range of relative risk aversion between 1 and 3 , the risk-free rate induced by the model varies between $1.87 \%$. and $0.56 \%$ This is true because in our setup, as the coefficient of relative risk aversion increases, the precautionary savings dominate the intertemporal substitution effect faster than the standard model and generate a lower interest rate.

\section{Expected Returns and the Utility Curvature $\gamma$}

FIGURE 2 shows how the equity premium, risk free rate and equity returns vary with the utility curvature $\gamma$. As the $\gamma$ increases, the agents become more risk averse to any bet. In this model, the precautionary savings plays an important role because households are afraid of bad times in which the financial obligations ratio is high. Since the households are restricted by the borrowing constraint and they cannot leverage more due to the already-capped financial obligations ratio, they will demand more of precautionary savings (treasury bond investments) to smooth their consumption for bad states of the economy.

This higher demand for risk free bonds will pull up the bond price $q_{t}$ and thus decrease the risk-free rate. This is the dotted line showing the risk-free rates for different values of risk aversion between 1 and 3. Having invested more in treasury bonds, the demand for equity investment will decrease and the expected equity returns will go up for the higher values of $\gamma$. The dashed line shows the equity returns for different values of risk aversion. Hence, by generating higher equity returns and lower risk-free rates, the model is 
able to get close to the equity risk premium observed in the data. The solid line in FIGURE 2 depicts the equity risk premium generated by the model versus the different values for utility curvature.

\section{FIGURE 2 EXPECTED RETURNS AND THE COEFFICIENT OF RISK AVERSION $\gamma$}

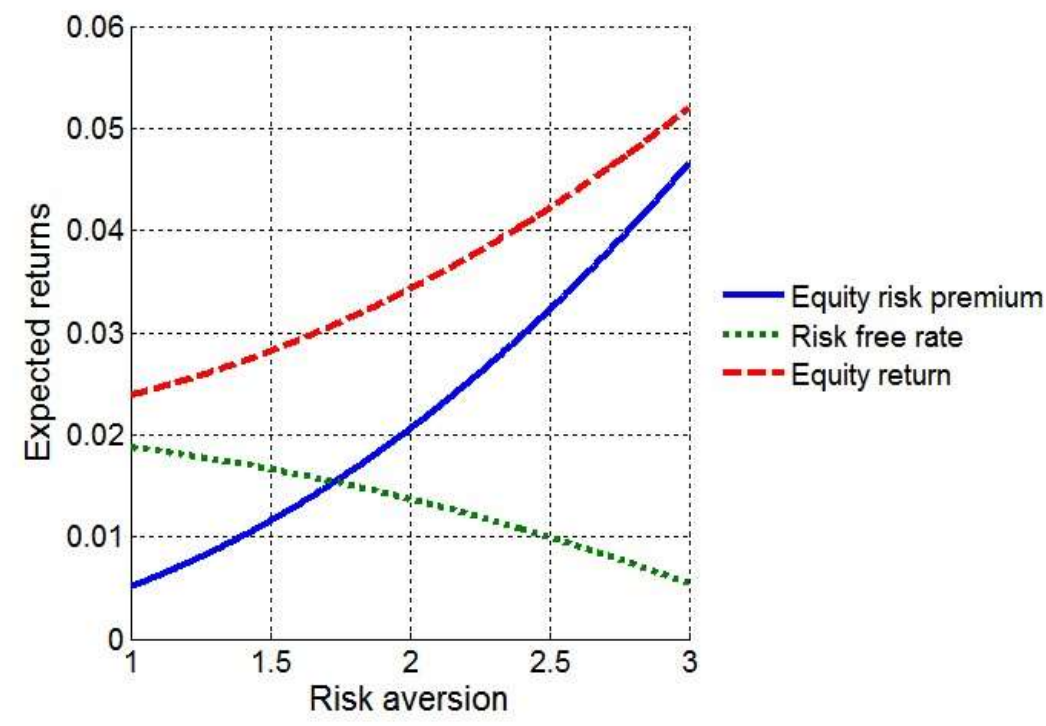

\section{Expected Returns and the Borrowing Constraint}

FIGURE 3 shows how the equity premium, the risk-free rate and equity returns vary with the household's obligation ratio $\theta$. Recall that financial obligations ratio is a direct indicator of the borrowing constraint in our model, so relaxing the borrowing constraint is equivalent to increasing the household financial obligations ratio cap $\theta$. FIGURE 3 indicates that as we relax the borrowing constraint, the equity risk premium shrinks which is numerically consistent with results in (Constantinides, Donaldson and Mehra, 2002).

FIGURE 3

\section{EXPECTED RETURNS AND THE HOUSEHOLD'S OBLIGATION RATIO $\theta$}

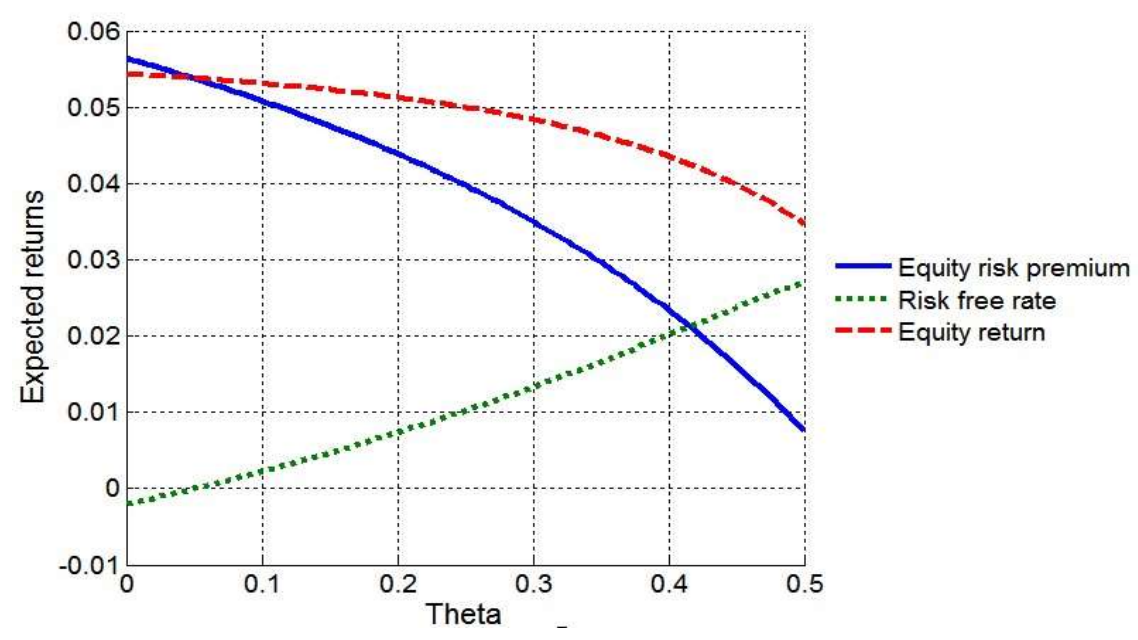


The intuition is straight forward. According to the financial obligation's ratio constraint (the borrowing constraint) in (2), households choose a debt service level that cap their financial obligations ratio at any time. Hence as this $\theta$ increases, agents can smooth their consumption much easier via larger borrowings. This leads to a decrease in the demand for precautionary savings (treasury bond investments), driving down bond prices $q_{t}$ and increasing the risk-free rate. This is the dotted line in FIGURE 3. From the other hand, as $\theta$ increases, the households have more funding resources for their consumption purposes and they can make more investments. The level of equity investment will increase (as more borrowings are to be consumed and the investment portfolio is more toward equity investment rather than bond investment) leading to lower equity returns. The dashed line shows the equity returns for different range of values for $\theta$. These two effects will decrease the equity premium as the level of $\theta$ increases, The solid line in FIGURE 3.

\section{Linearizing the Pricing Kernel}

In this section, I explore how the model proposed in section 3 is able to generate a more volatile kernel while keeping the risk-free interest rate low. The linearized version of the stochastic discount factor is:

$$
M_{t+1}=\beta\left(\frac{C_{t+1}}{C_{t}}\right)^{-\gamma}\left(\frac{s_{t+1}}{s_{t}}\right)^{-\gamma}=\beta \exp \left\{(-\gamma)\left(\ln \frac{C_{t+1}}{C_{t}}\right)\right\} \exp \left\{(-\gamma)\left(\ln \frac{s_{t+1}}{s_{t}}\right)\right\}
$$

where $C_{t}$ is aggregate consumption and $S_{t}$ is the surplus consumption ratio defined as $S_{t}=\frac{C_{t}-G_{t}}{C_{t}}$. $G_{t}$ is aggregate financial obligations in period $t$. Taking the logarithm from both sides and letting $c_{t}=\ln \left(C_{t}\right)$ and $s_{t}=\ln \left(S_{t}\right)$ result in the following:

$\ln M_{t+1}=\ln \beta+(-\gamma)\left(c_{t+1}-c_{t}\right)+(-\gamma)\left(s_{t+1}-s_{t}\right)$

Now, some simplifying assumptions need to be made. For aggregate U.S. data on per capita consumption of nondurables and services, a good approximation to the data is the following model that makes the growth in the log of per capita consumption a random walk with drift:

$c_{t}=\mu_{c}+c_{t-1}+\sigma_{c} \epsilon_{t}$, where $\epsilon_{t} \quad$ i.i.d. $\sim N(0,1)$

Assuming that the growth in the surplus consumption ratio also follows a random walk,

$s_{t}=\mu_{d}+s_{t-1}+\sigma_{d} \epsilon_{t}, \quad$ where $\epsilon_{t} \quad$ i.i.d. $\sim N(0,1)$

Note that $\mu_{d}$ and $\sigma_{d}$ are the drift term and standard deviation term of the random walk process for the surplus consumption ratio. Now using (39) and (40) in (41) result in the following:

$\ln M_{t+1}=\ln \beta+(-\gamma)\left(\mu_{c}+\sigma_{c} \epsilon_{t}\right)+(-\gamma)\left(\mu_{d}+\sigma_{d} \epsilon_{t}\right)$

Because $\epsilon_{t}$ is i.i.d. $\sim N(0,1)$, then $\ln M_{t+1}$ is also normally distributed with mean $\mu$ and variance $\sigma^{2}$ :

$\mu=\ln \beta+(-\gamma) \mu_{c}+(-\gamma) \mu_{d}$

$\sigma^{2}=(-\gamma)^{2} \sigma_{c}^{2}+(-\gamma)^{2} \sigma_{d}^{2}$

Now consider the following property of normal distribution: If $\log X \sim N\left(\mu_{x}, \sigma_{x}^{2}\right)$, then $E(X)=\exp \left(\mu_{x}+\right.$ $\left.\frac{\sigma_{x}^{2}}{2}\right)$ and $\operatorname{std}(X)=E(m) \sqrt{\exp \left(\sigma^{2}\right)-1}$. From this property $E\left(M_{t+1}\right)$ and $\sigma\left(M_{t+1}\right)$ can be derived as follows: 


$$
\text { Now } \begin{aligned}
E(M) & =\exp \left(\mu+\frac{\sigma^{2}}{2}\right) \\
\sigma(M) & =E(M) \sqrt{\exp \left(\sigma^{2}\right)-1}
\end{aligned}
$$

Having $E(M)$ and $\sigma(M)$ in hand, I can now derive an equation for gross risk-free rate $R_{F}$ and explain the intuition behind:

$$
R_{f}=E(M)^{-1} \Rightarrow \ln \left(R_{f}\right)=\ln \left(1+r_{f}\right)=-\ln E(M)=-\ln \left(\exp \left(\mu+\frac{\sigma^{2}}{2}\right)\right)=-\mu-\sigma^{2} / 2
$$

Using equations (45) and (46), the approximate risk-free rate is:

$$
r_{f} \approx-\ln \beta+\gamma \mu_{c}+\gamma \mu_{d}-\gamma^{2} \frac{\sigma_{c}^{2}}{2}-\gamma^{2} \frac{\sigma_{d}^{2}}{2}
$$

Equation (48) has some important implications. There are five terms in this equation that according to the set-up of my model can be interpreted as follows:

1. $-\ln \beta$ : As $\beta$, the time discount factor decreases, agents become less patient and require higher interest rates to substitute consumption over time. For example, if $\beta$ is calibrated to 0.99 , this means that approximately $1 \%$ of the risk-free rate is due to time preferences.

2. $\gamma \mu_{c}$ : For $\gamma>0$, this implies that as consumption growth increases, individuals should be compensated with higher interest rates to sacrifice today's consumption for tomorrow's consumption.

3. $\gamma \mu_{d}$ : For $\gamma>0$, this implies that in recessions, when consumption gets close to financial obligations, the surplus consumption ratio decreases and investors require higher interest rates.

4. $-\gamma^{2} \frac{\sigma_{c}^{2}}{2}$ : Analogous to standard consumption-based models, this part of equation (B.9) can be interpreted as precautionary savings. The coefficient of consumption growth volatility is negative, implying that as consumption growth becomes more volatile, precautionary savings push the interest rate down.

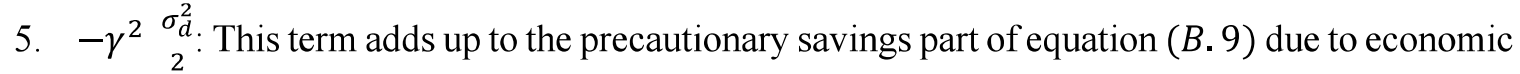
uncertainties. As the volatility of the surplus consumption ratio increases, demand for safer assets increases which leads to lower interest rates. This is what enables my model - unlike the standard consumption-based model - to generate lower risk-free rates for higher coefficients of risk aversion.

\section{CONCLUSION}

In an infinitely lived representative agent endowment economy, this paper addresses how the household financial obligations impact the equity risk premium. The impact is studied under two different channels, the preference channel and the borrowing constraint channel. Financial obligations ratio is a countercyclical indicating variable that affects agents' marginal utility of consumption and reinforces its countercyclicality over business cycles. This is the driving force of the model. At the equilibrium, by specifying an explicit Markov process for consumption growth, in a non-stationary environment, I derive the expected returns on equity and the risk-free bond and calculate the equity risk premium. I show that in a reasonably calibrated economy, the model is able to generate the observed equity premium in U.S. data while keeping the risk-free rate low. 


\section{REFERENCES}

Abel, A.B. (1990). Asset prices under habit formation and catching up with the joneses. American Economic Review, 80, 38-42.

Barro, R. (2006). Rare disasters and asset markets in the twentieth century. Quarterly Journal of Economics.

Brown, T.K., \& Price, S.W. (2005). Debt and distress: evaluating the psychological cost of credit. Journal of Economic Psychology, 42, 642-663.

Campbell, J.Y., \& Cochrane, J.H. (1999). By force of habit: A consumption-based explanation of aggregate stock market behavior. Journal of Political Economy, 107, 205-251.

Chetty, R., \& Szeidl, A. (2007). Consumption commitments and risk preferences. The Quarterly Journal of Economics, 122(2), 831-877.

Cochrane, J.H. (2005). Financial markets and the real economy. Working Paper 11193, National Bureau of Economic Research.

Cochrane, J.H. (2016). Macro-finance.

Constantinides, G.M., \& Duffie, D. (1996). Asset pricing with heterogeneous consumers. Journal of Political Economy, 104, 219-240.

Constantinides G. (1990). Habit formation: A resolution of the equity premium puzzle. Journal of Political Economy, 98, 519-543.

Donaldson Constantinides, G.M., \& Mehra, R. (2002). Junior can't borrow: A new perspective on the equity premium puzzle. Quarterly Journal of Economics, 118, 269-296.

Dickey, D.A., \& Fuller, W. (1979). Distribution of the estimators for autoregressive time series with a unit root. Journal of the American Statistical Association, 74, 427-431.

Dynan, K. (2012). Is a household debt overhang holding back consumption? Brookings Papers on Economic Activity.

Dynan, K., \& Edelberg, W. (2013). The relationship between leverage and household spending behavior: Evidence from the 2007-2009 survey of consumer finances. Federal Reserve Bank of St. Louis Review, 95, 425-448.

Epstein, L.G., \& Zin, S.E. (1991). Substitution, risk aversion and the temporal behavior of asset returns. Journal of Political Economy, 99, 263-286.

Jahangiry, P. (2019). Households' financial obligations and the cross-section of stock returns: FCAPM. Working paper.

Jahangiry, P. (2020). Predictability of stock returns with household's obligation ratio. Working paper.

Johnson, K.W., \& Li, G. (2007). Do high debt payments hinder household consumption smoothing? Finance and Economics Discussion Series (FEDS), 52.

Johnson, K.W., \& Li, G. (2010). The debt-payment-to-income ratio as an indicator of borrowing constraints: Evidence from two household surveys. Journal of Money, Credit and Banking, 42, $1373-1390$.

Juselius, M., \& Drehmann, M. (2012). Do debt service costs affect macroeconomic and financial stability? BIS Quarterly Review, pp. 21-34.

Juselius, M., \& Drehmann, M. (2015). Leverage dynamics and the real burden of debt. BIS Quarterly Review.

Lucas, R. (1978). Asset Prices in an Exchange Economy. Econometrica, 46(6),1429-45.

Mehra, R., \& Prescott, E.C. (1985). The equity premium: A puzzle. Journal of Monetary Economics, 15, $145-161$.

Piazzesi, S., \& Tuzel. (2007). Housing, consumption and asset pricing. Journal of Financial Economics, $83,581-612$.

Richardson, E.P., \& Roberts, R (2013). The relationship between personal unsecured debt and mental and physical health: A systematic review and meta-analysis. Clinical Psychology Review, 33, 1148 1162.

Rytchkov, O. (2014). Asset Pricing with Dynamic Margin Constraints. Journal of Finance, 69(1).

Sahalia, P., \& Yogo. (2004). Luxury goods and the equity premium. Journal of Finance, 59, 2959-3004. 


\section{APPENDIX}

From Federal Reserve's Board: The household Debt Service Ratio (DSR) is the ratio of total required household debt payments to total disposable income. The DSR is divided into two parts: Mortgage DSR and Consumer DSR. The Mortgage DSR is total quarterly required mortgage payments divided by total quarterly disposable personal income. The Consumer DSR is total quarterly scheduled consumer debt payments divided by total quarterly disposable personal income. The Mortgage DSR and the Consumer DSR sum to the DSR. Quarterly values for the Debt Service Ratio are available from 1980 forward.

The limitations of current sources of data make the calculation of the ratio especially difficult. The ideal data set for such a calculation would have the required payments on every loan held by every household in the United States. Such a data set is not available, and thus the calculated series is only an approximation of the debt service ratio faced by households. Nonetheless, this approximation is useful to the extent that, by using the same method and data series over time, it generates a time series that captures the important changes in the household debt service burden. The series are revised as better data or improved methods of estimation become available. To create the measure, payments are calculated separately for revolving debt and for each type of closed-end debt, and the sum of these payments is divided by disposable personal income as reported in the National Income and Product Accounts. For revolving debt, the assumed required minimum payment is 2-1/2 percent of the balance per month. This estimate is based on the January 1999 Senior Loan Officer Opinion Survey, in which most banks indicated that required monthly minimum payments on credit cards ranged between 2 percent and 3 percent, a ratio that apparently had not changed substantially over the previous decade.

Payments on closed-end loans, which are calculated for each major category of closed-end loan, are derived from the loan amount outstanding, the average interest rate, and the average remaining maturity on the stock of outstanding debt. Estimates of the amount of mortgage debt are taken from the Federal Reserve Board's Z.1 Financial Accounts of the United States statistical release, and estimates of outstanding consumer debt are taken from the Federal Reserve's G.19 Consumer Credit statistical release. For consumer debt, a more detailed breakdown by type of closed-end loan is obtained using internal Federal Reserve estimates and data from the Federal Reserve's Survey of Consumer Finances (SCF). Interest rates on closed-end consumer loans are obtained from the Federal Reserve Board's G.19 Consumer Credit and G.20 Finance Companies statistical releases, the SCF, and additional proprietary data sources. An estimate of the interest rate on the stock of outstanding debt is obtained by weighting the recent history of interest rates using information on the age of outstanding loans in the SCF. The interest rate on the stock of outstanding mortgage debt is an estimate provided by the Bureau of Economic Analysis. Maturity series for consumer debt are taken from the SCF. Maturity series for mortgage debt are calculated using data from Lender Processing Services and Mortgage Bankers Association.

The financial obligations Ratio is a broader measure than the Debt Service Ratio. It includes rent payments on tenant-occupied property, auto lease payments, homeowners' insurance, and property tax payments. These statistics are obtained from the National Income and Product Accounts. 